\title{
Clinical Outcome of Low Dose Contrast during Percutaneous Coronary Intervention in Patients with Moderate to Severe Kidney Impairment
}

\author{
Wassam Eldin Elshafey, Walaa Farid Abdel Aziz, \\ Ahmed Magdy Kamal Eldin, Mohamed Mahmoud Khattab \\ Menoufia University, Shibin El Kom, Al Minufya, Egypt \\ Email: dr_wesamhadad@yahoo.com
}

How to cite this paper: Elshafey, W.E., Aziz, W.F.A., Eldin, A.M.K. and Khattab, M.M. (2019) Clinical Outcome of Low Dose Contrast during Percutaneous Coronary Intervention in Patients with Moderate to Severe Kidney Impairment. World Journal of Cardiovascular Diseases, 9, 781-795.

https://doi.org/10.4236/wjcd.2019.911070

Received: September 6, 2019

Accepted: November 5, 2019

Published: November 8, 2019

Copyright $\odot 2019$ by author(s) and Scientific Research Publishing Inc. This work is licensed under the Creative Commons Attribution International License (CC BY 4.0).

http://creativecommons.org/licenses/by/4.0/

\begin{abstract}
Background: Chronic kidney disease patients are at a greater risk for nephropathy requiring dialysis after percutaneous coronary intervention. Such patients are usually deferred due to fear of "Renalism". Objectives This study assesses the outcome of Low dose contrast protocol during PCI in CKD patients whose e-GFR $<60 \mathrm{ml} / \mathrm{min} / 1.72 \mathrm{~m}$ and investigates a safety margin for contrast use in these high-risk categories. Methods: Patients were into three groups according to CV/e-GFR ratio: Group (A) low-dose: CV/e-GFR ratio $<2.0$ Group (B) medium-dose: CV/e-GFR ratio $>2.0$ and $<$ MACD ( $5 \times$ bodyweight $\backslash$ s.creatinine). Group (C) high-dose: CV/e-GFR ratio > MACD. Results: A total of 73 patients were enrolled. Average age was $54 \pm 8$ years, $81.4 \%$ were male and $18.6 \%$ were females and $52 \%$ were diabetic. Mean baseline e-GFR was $40 \pm 8.0 \mathrm{ml} / \mathrm{min} / 1.73 \mathrm{~m}^{2}$. Contrast Volume used in group A was $(58.26 \pm 15.05)(\mathrm{n}=24)$, in group B $(109.42 \pm$ 17.11) $(\mathrm{n}=26)$ and in group $C(304.5 \pm 60.30)(\mathrm{n}=23)$, respectively. The incidences of CI-AKI in the 3 groups were $0 \%, 11.5 \%$ and $35 \%$, respectively $(\mathrm{p}=0.02)$. All-cause death $0 \%, 17 \%$ and introduction of maintenance hemo dialysis was $0 \%, 11.5 \%$ and $26 \%$, respectively $(\mathrm{p}<0.01)$. Conclusion: Low dose contrast protocol is safe, effective and easily applicable technique without CI-AKI or death. CV/e-GFR $<2$ is a safe ratio and can be achieved without IVUS use with good outcomes.
\end{abstract}

\section{Keywords}

Chronic Kidney Disease (CKD), Maximum Allowed Contrast Dose (MACD), Contrast Induced Acute Kidney Injury (CI-AKI), Low Dose Protocol, Contrast Volume to e-GFR Ratio 


\section{Introduction}

Contrast-induced acute kidney injury (CI-AKI) is one of the complications following coronary angiography (CAG) and percutaneous coronary intervention (PCI), especially among patients with chronic kidney disease [1]. CI-AKI after PCI has a poor prognosis and is at high risk for major adverse cardiac and cerebrovascular events (MACCE) in the long-term clinical course [2] [3] [4] [5].

Prophylaxis against CI-AKI using drugs such as $\mathrm{N}$-acetylcysteine, sodium bicarbonate, or atrial natriuretic peptide remains controversial [6] [7]. Also, prophylactic hemodialysis done after cardiac catheterization or intervention in patients with CKD is proved not to prevent CI-AKI [8]. Although currently, an evidence-based strategy has been limited to volume hydration before, during and after the procedure, A new study named AMACING Trial challenges the Cornerstone of Prophylaxis i.e. IV hydration. In a randomized trial comparing intravenous saline to no hydration, patients at high risk for contrast nephropathy gained no added protection from hydration during elective procedures that required iodinated contrast. "The AMACING study found that no prophylaxis is to be not inferior to prophylactic intravenous hydration in the prevention of contrast-induced nephropathy, as well as cost-saving". Moreover, they add that hydration itself appeared to increase the risk of complications [9]. Therefore, CKD patients are still deferred from intervention, due to this fear of "Renalism" [10].

Some literature reported a significant correlation of contrast volumes with the incidence of CI-AKI, thus techniques to minimize contrast seem to be the most effective in preventing CI-AKI especially in patients with moderate and severe kidney impairment AKI [11] [12] [13] [14] [15]. In this study, we are trying to prove that PCI can be done in these patients safely and assessing incidence of CI-AKI after PCI as well as, trying to investigate a safety margin of contrast below which contrast use can be safe without need for dialysis or occurrence of CI-AKI these high-risk patients.

\section{Aim of Study}

To asses incidence of CI-AKI in patients with moderate to severe kidney impairment undergoing PCI using a contrast minimizing technique "Low dose contrast protocol " as well as investigating a safety margin for contrast use in these patients.

\section{Patients and Methods}

This study is a single-center, prospective study aiming to asses clinical outcome of PCI both elective and primary in chronic kidney disease patients with moderate and severe degrees using a contrast minimizing technique. We called the technique "Low dose contrast protocol". Also, we are investigating a cut-off value for safe contrast use in such patients.

Study population Inclusion Criteria:

1) Patients eligible for PCI according to European Society of Cardiology 


\section{(ESC) guidelines [16]:}
a) Acute ST-elevation myocardial infarction (STEMI).
b) Non-ST-elevation acute coronary syndrome (NSTE-ACS).
c) Unstable angina.
d) Chronic Stable angina.
e) Anginal equivalent (eg, dyspnea, arrhythmia, or dizziness).
f) Evidence of myocardial ischemia on non invasive stress testing.

2) CKFD Patients with moderate to severe renal impairment (e-GFR $<60$ $\mathrm{ml} / \mathrm{min} / 1.72 \mathrm{~m}$ ).

\section{Exclusion criteria:}

a) End stage renal disease (patients on regular dialysis) or very severe impairment of renal functions GFR $<15 \mathrm{ml} / \mathrm{min} / 1.73 \mathrm{~m}$.

b) Severly impaired systolic function $(\mathrm{EF}<35 \%)$.

c) Decompensated heart failuresymptomps and signs e.g. congested neck veins, lower limb oedema and pulmonary venous congestion.

d) Hypersensitivity or allergy to contrast material.

e) Recent exposure to contrast material within 7 days.

\section{Endpoints:}

Primary endpoints are occurrence of death due to any cause or hemodialysis after procedure and during in-hospital course. Secondary endpoints include development of CIN with rise of, $5 \mathrm{mg} / \mathrm{dl}$ of serum creatinine or $25 \%$ of baseline, occurrence of stroke, MI and death.

\section{Laboratory examination:}

Serum creatinine was measured pre and post procedure and then estimated glmoerular filtration rate was calculated for all patients using the Japanese Modification of Diet in Renal Disease (MDRD) study equation released by the Japanese Society of Nephrology [17].

$$
\begin{aligned}
\text { Estimated GFR }\left(\mathrm{ml} / \mathrm{min} / 1.73 \mathrm{~m}^{2}\right) & =186 \times(\text { Creat } / 88.4)^{-1.154} \times(\text { Age })^{-0.203} \\
& \times(0.742 \text { if female }) \times(1.210 \text { if black })
\end{aligned}
$$

\section{Patient subgroups:}

Patients are divided according to contrast volume to e-GFR ratio into 3 groups:

a) Group A: 24 patients had PCI using low dose contrast protocol, CV/e-GFR ratio $<2$.

b) Group B: 26 patient had PCI with moderate amount of dye, CV/e-GFR $>2$ and less than MACD.

c) Group C: 23 patient had PCI using large amounts of dye, CV/e-GFR > MACD.

Pci procedure:

Use small diameter catheters (i.e., 5 - 6 French) without side-holes.

Limit the volume of contrast injected from the catheter to $1-2 \mathrm{~cm}^{3}$ per injection using a $3-\mathrm{cm}$ syringe.

Procedures were done using low osmolar contrast. 
All contrast injections require simultaneous cine angiogram, i.e. "no dye without the cines eye."

During PCI, before the exchange of devices such as balloon catheters, remove contrast from the guide catheter by back bleeding contrast out of the " $\mathrm{Y}$ " connector.

If available, display previous angiographic images (including angiography from past procedures) alongside active fluoroscopy screen as a reference to use as guidance during guide wire, balloon, stent.

Absolutely no contrast "puffing" during the procedure. Minimizing contrast during procedure by using $\mathrm{CV} /$ gfr ratio $<2$.

Mixing saline with dye although it decreases lesion opacification.

IVUS using to maximize contrast restriction was not available, hence we targeted a reasonable ratio $\mathrm{cv} / \mathrm{eGfr}<2$ and we called this approach low dose contrast.

\section{Statistics:}

Continuous variables were expressed as mean \pm SD Categorical variables were expressed as counts and percentages, and the Chi-square test \& Annova test \& student t-test \& Kruskal Wallis test and Whitney man u test was used for comparison. ROC curve analysis was done to predict cut off value for CIN incidence using cv/e-GFR ratio and (sensitivity \& specify) for all patients as well as diabetic and non-diabetics and All analyses were performed with the SAS 9 (Figures 1-3).

\section{Results}

\section{Patient characteristics}

This study included 73 patients presented to the Menoufia university hospital

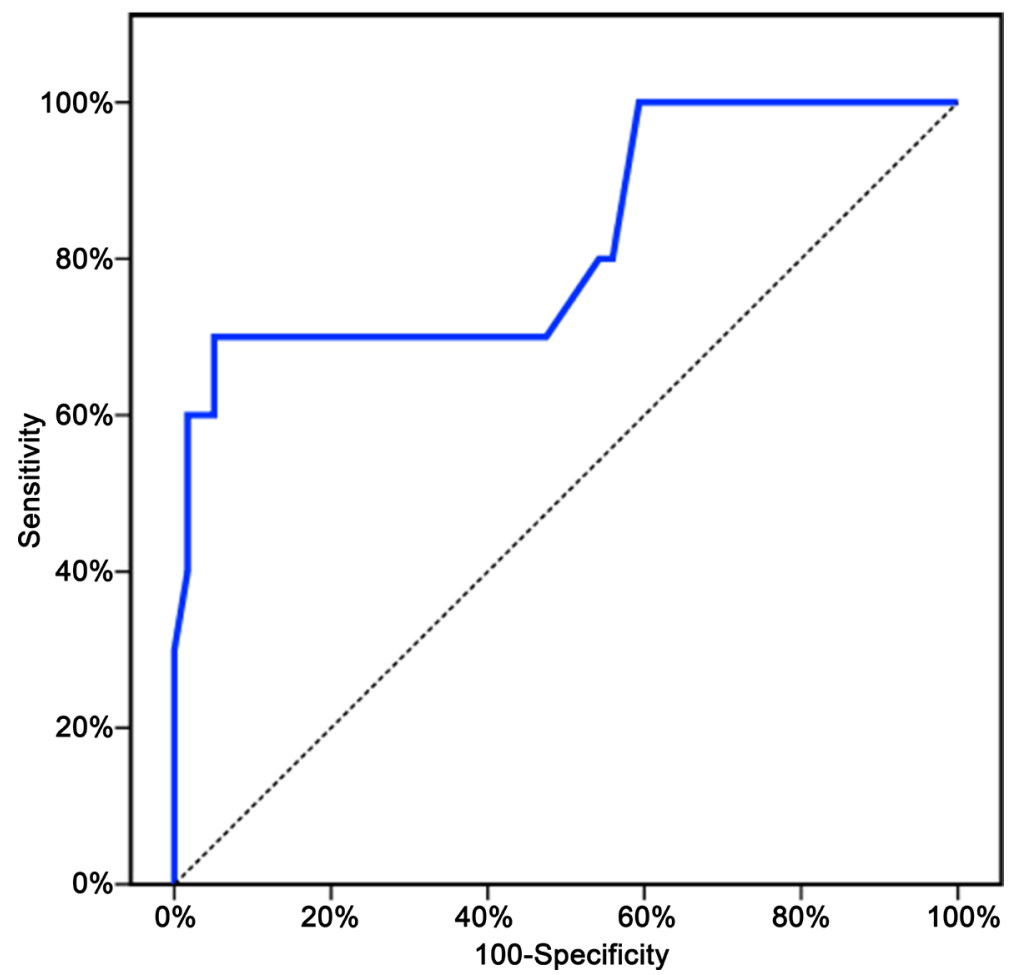

Figure 1. ROC curve for CV. E-GFR to predict CIN cases for total sample $(n=73)$. 


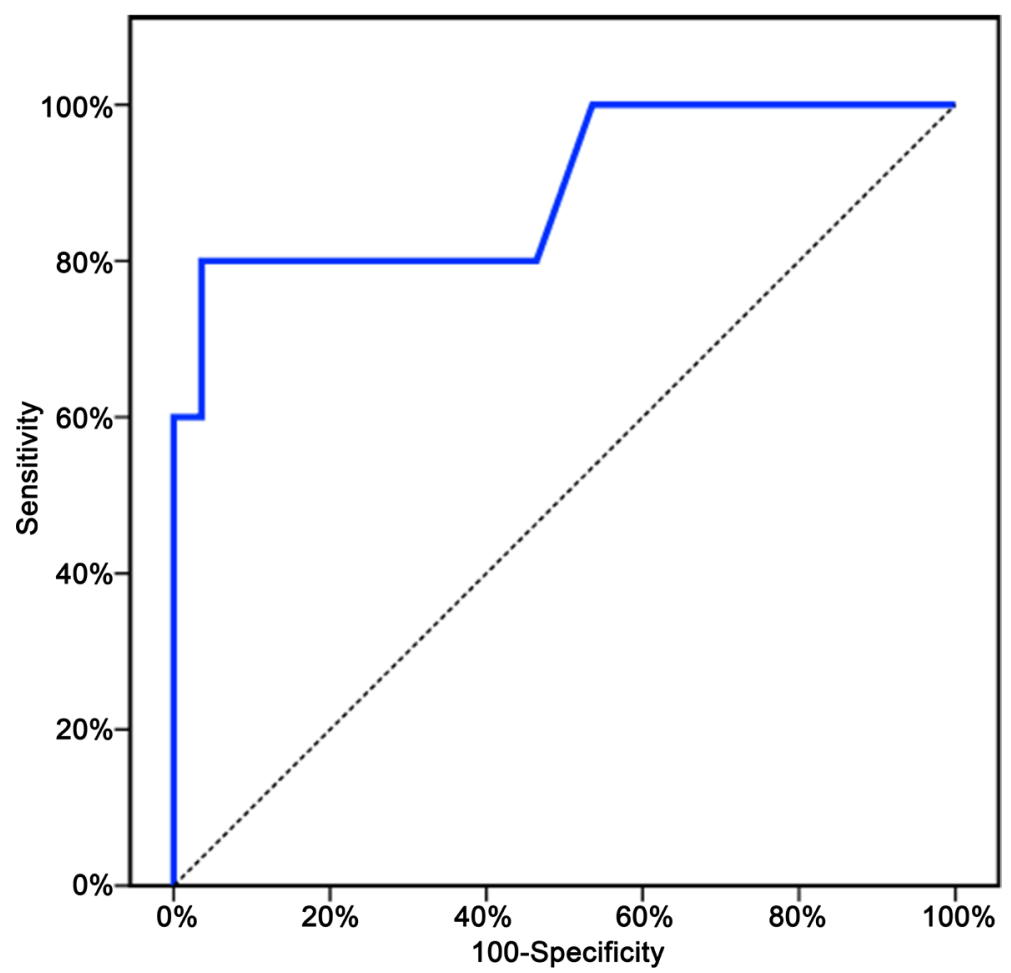

Figure 2. ROC curve for CV. eGFR to predict CIN cases for non-diabetic cases $(\mathrm{n}=35)$.

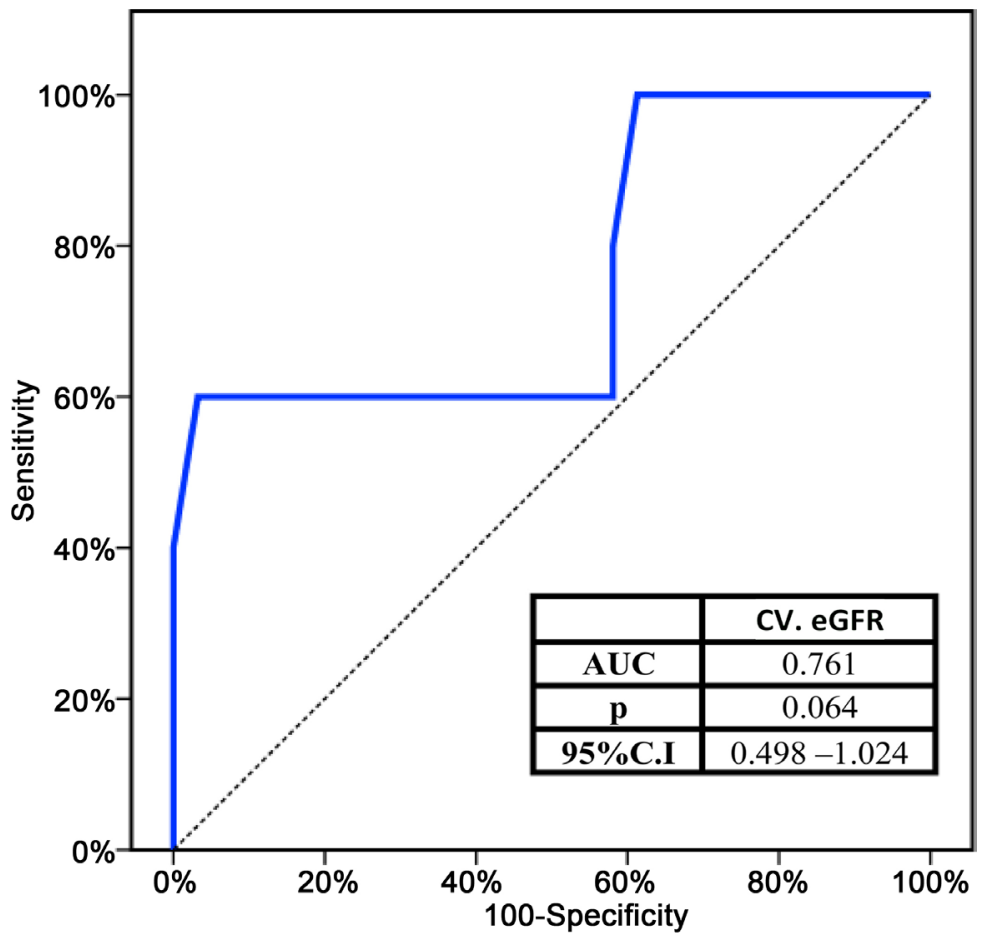

Figure 3. ROC curve for CV. eGFR to predict CIN cases for diabetic cases $(n=38)$.

and the National Heart Institute with coronary artery disease either stable or acute coronary syndrome associated with CKD whose e-GFR were less than 60 $\mathrm{m} / \mathrm{min} / 1.73$ and were treated with either primary or elective PCI, and they were 
investigated for the occurrence of contrast-induced nephropathy (CIN)), defined as an increase of $25 \%$ or more or an absolute increase of $0.5 \mathrm{mg} / \mathrm{dl}$ or more in serum creatinine level from baseline value (measured on admission) within 48 72 hours of radio-contrast administration.

Patients were divided into 3 groups according to the contrast dose Table 1 .

(18\%) 17 patients were females and 57 patients were males (81.4\%) and mean age among the total patients was $54 \pm 8$ and mean body weight was $85 \pm 6 \mathrm{~kg}$ among patients.

There was no statistically significant difference between the 3 groups as regards to age, sex or body weight Table 2.

Group A 17 patients were smokers (73.9\%), 12 patients were diabetic (52.2\%), 10 patients were hypertensives $(43.5 \%)$ and 6 patients were dyslipidemics (26.6\%).

Group B 21 patients were smokers (80.8\%), 14 patients were diabetic (53.8\%), 10 patients were hypertensives (38.5\%) and 5 patients were dyslipidemics $(19.2 \%)$.

Group C 12 patients were smokers (60\%), 12 patients were diabetic (50.0\%), 13 patients were hypertensives (65\%) and 3 patients were dyslipidemics (15\%).

Overalincidence of dyslipidemia 18\%, 52\% Diabetes, $45.2 \%$ hypertension and $68.4 \%$ smokers.

There is no statistically significant difference as regard risk factors (HTN, DM,

Table 1. Distribution of the studied cases according to $(n=73)$.

\begin{tabular}{ccc}
\hline & No. & $\%$ \\
\hline Low-dose (group A) & 24 & 33.3 \\
Medium-dose (group B) & 26 & 37.7 \\
High-dose (group C) & 23 & 29.0 \\
\hline
\end{tabular}

Table 2. Comparison between the three studied groups according to demographic data.

\begin{tabular}{|c|c|c|c|c|c|c|c|c|}
\hline & \multicolumn{2}{|c|}{ Group A $(n=24)$} & \multicolumn{2}{|c|}{ Group B $(n=26)$} & \multicolumn{2}{|c|}{ Group C $(n=23)$} & \multirow{2}{*}{$\begin{array}{c}\text { Test of } \\
\text { Sig. }\end{array}$} & \multirow{2}{*}{$\mathrm{p}$} \\
\hline & No. & $\%$ & No. & $\%$ & No. & $\%$ & & \\
\hline \multicolumn{9}{|l|}{ Gender } \\
\hline Male & 18 & 78.3 & 21 & 80.8 & 17 & 79.8 & \multirow[t]{2}{*}{$F=0.383$} & $\begin{array}{c}\mathrm{MCp}= \\
0.925\end{array}$ \\
\hline Female & 6 & 21.7 & 5 & 19.2 & 6 & 20.2 & & \\
\hline \multicolumn{9}{|l|}{ Age (years) } \\
\hline Min. - Max. & \multicolumn{2}{|c|}{$36.0-70.0$} & \multicolumn{2}{|c|}{$40.0-75.0$} & \multicolumn{2}{|c|}{$36.0-80.0$} & & \\
\hline Mean \pm SD & \multicolumn{2}{|c|}{$52.70 \pm 10.03$} & \multicolumn{2}{|c|}{$55.81 \pm 8.12$} & \multicolumn{2}{|c|}{$55.50 \pm 9.67$} & $\mathrm{~F}=0.802$ & 0.453 \\
\hline Median & \multicolumn{2}{|l|}{54.0} & \multicolumn{2}{|l|}{54.0} & \multicolumn{2}{|l|}{55.50} & & \\
\hline \multicolumn{9}{|l|}{ Weight (kg) } \\
\hline Min. - Max. & \multicolumn{2}{|c|}{$70.0-105.0$} & \multicolumn{2}{|c|}{$66.0-105.0$} & \multicolumn{2}{|c|}{$74.0-101.0$} & & \\
\hline Mean \pm SD & \multicolumn{2}{|c|}{$84.0 \pm 8.80$} & \multicolumn{2}{|c|}{$83.88 \pm 9.95$} & \multicolumn{2}{|c|}{$86.25 \pm 7.26$} & $F=0.485$ & 0.618 \\
\hline Median & \multicolumn{2}{|l|}{82.0} & \multicolumn{2}{|l|}{85.0} & \multicolumn{2}{|l|}{86.0} & & \\
\hline
\end{tabular}


Smoking and dyslipidemia) Table 3.

The mean ejection fraction was $51.43 \pm 9.43$ in group $\mathrm{A}$, while in group $\mathrm{B}$ was $51.46 \pm 8.02$ and in group $C$ was $47.25 \pm 9.80$. There was no statistically significance between the 3 groups $(\mathrm{p}=0.223)$ Table 4 .

Pre GFR in group A was ranging from 22.38 to 58.25 and in group B was ranging from 22.9 to 58.25 while in group 3 from 24.4 to 58.0 without any clinical significance $[\mathrm{p}=0.091]$ ( Table 5).

ROC curve analysis between contrast volume and Egfr showed that CV/Egfr > 6 is the cut off value to predict CIN in total number of patients with sensitivity of $70 \%$ and specifity of $94.92 \%$ and $70 \%$ ppv and $94.9 \%$ NPV (Table 6 ).

$\mathrm{CV} / \mathrm{Egfr}>5.2$ is the cut off value to predict $\mathrm{CIN}$ in non diabetic patients with sensitivity of $80 \%$ and specifity of $96.43 \%$ and $80 \%$ ppv and 96.4 NPV (Table 7).

Table 3. Comparison between the three studied groups according to risk factors.

\begin{tabular}{|c|c|c|c|c|c|c|c|c|}
\hline & \multicolumn{2}{|c|}{ Group A $(n=24)$} & \multicolumn{2}{|c|}{ Group B $(n=26)$} & \multicolumn{2}{|c|}{ Group C $(n=23)$} & \multirow{2}{*}{$x^{2}$} & \multirow{2}{*}{$\mathrm{p}$} \\
\hline & No. & $\%$ & No. & $\%$ & No. & $\%$ & & \\
\hline Smoker & 17 & 73.9 & 21 & 80.8 & 12 & 60.0 & 2.480 & 0.289 \\
\hline $\mathrm{DM}$ & 12 & 52.2 & 14 & 53.8 & 12 & 50.0 & 0.067 & 0.967 \\
\hline HTN & 10 & 43.5 & 10 & 38.5 & 13 & 65.0 & 3.452 & 0.178 \\
\hline Dyslipidaemia & 6 & 26.1 & 5 & 19.2 & 3 & 15.0 & 0.846 & $\mathrm{MCp}=0.700$ \\
\hline
\end{tabular}

$\chi^{2}$ : Chisquaretest; MC: Monte Carlo; $\mathrm{p}: \mathrm{p}$ value for comparing between the three groups; ${ }^{*}$ : Statistically significant at $\mathrm{p} \leq 0.05$.

Table 4. Comparison between the three studied groups to (EF).

\begin{tabular}{cccccc}
\hline EF & Group A $(\mathrm{n}=24)$ & Group B $(\mathrm{n}=26)$ & Group C $(\mathrm{n}=23)$ & $\mathrm{F}$ & $\mathrm{p}$ \\
\hline Min. - Max. & $30.0-65.0$ & $35.0-65.0$ & $30.0-70.0$ & & \\
Mean \pm SD. & $51.43 \pm 9.43$ & $51.46 \pm 8.02$ & $47.25 \pm 9.80$ & 1.533 & 0.223 \\
Median & 50.0 & 51.50 & 45.0 & & \\
\hline
\end{tabular}

Table 5. Comparison between the three studied groups according to cv. Egfr and Pre GFR.

\begin{tabular}{|c|c|c|c|c|c|c|c|c|}
\hline & \multirow{2}{*}{$\begin{array}{c}\text { Group A } \\
(\mathrm{n}=24)\end{array}$} & \multirow{2}{*}{$\begin{array}{l}\text { Group B } \\
(n=26)\end{array}$} & \multirow{2}{*}{$\begin{array}{l}\text { Group C } \\
(n=23)\end{array}$} & \multirow{2}{*}{$\mathrm{F}$} & \multirow{2}{*}{$\mathrm{p}$} & \multicolumn{3}{|c|}{ Post hoc test } \\
\hline & & & & & & A vs. B & A vs. C & B vs. C \\
\hline \multicolumn{9}{|l|}{ cv.eGFR } \\
\hline Min. - Max. & $0.60-1.90$ & $2.10-4.20$ & $4.10-11.0$ & \multirow{3}{*}{$118.304^{*}$} & \multirow{3}{*}{$<0.001^{*}$} & \multirow{3}{*}{$0.001^{*}$} & \multirow{3}{*}{$<0.001^{\star}$} & \multirow{3}{*}{$<0.001^{\star}$} \\
\hline Mean \pm SD & $1.47 \pm 0.38$ & $2.83 \pm 0.57$ & $6.93 \pm 2.10$ & & & & & \\
\hline Median & 1.50 & 2.70 & 6.45 & & & & & \\
\hline \multicolumn{9}{|l|}{ Pre GFR } \\
\hline Min. - Max. & $22.38-58.25$ & $22.90-58.25$ & $24.40-58.0$ & \multirow{3}{*}{$3.888^{*}$} & \multirow{3}{*}{$0.025^{*}$} & \multirow{3}{*}{0.797} & \multirow{3}{*}{$0.025^{*}$} & \multirow{3}{*}{0.091} \\
\hline Mean \pm SD & $37.69 \pm 10.06$ & $39.35 \pm 8.74$ & $45.07 \pm 8.06$ & & & & & \\
\hline Median & 38.17 & 40.0 & 44.80 & & & & & \\
\hline
\end{tabular}


$\mathrm{CV} / \mathrm{Egfr}>7$ is the cut off value to predict CIN in diabetic patients with sensitivity of $60 \%$ and specifity of $96.77 \%$ and $75 \%$ ppv and 93 NPV (Table 8).

Lesion and procedural characteristics

There was no statistically significant difference between the 3 groups Table 9 .

Contrast dye volume and clinical outcomes

In group A least amount used was $40 \mathrm{ml}$ and maximum amount was $80 \mathrm{ml}$ with mean $58.26 \pm 15.05 \mathrm{ml}$.

In group B $90 \mathrm{ml}$ contrast was the least amount of contrast used and $150 \mathrm{ml}$ was maximum amount used with $109.42 \pm 17.11 \mathrm{ml}$. In group C contrast volume was ranging between 200 and $450 \mathrm{ml}$ with mean $304.5 \pm 60.30 \mathrm{ml}$ Table 10 .

Table 6. Agreement (sensitivity, specificity) for CV. eGFR to predict CIN cases for total sample $(\mathrm{n}=73)$.

\begin{tabular}{cccccc}
\hline & Cut off & Sensitivity & Specificity & PPV & NPV \\
\hline CV. eGFR & $>6$ & 70.0 & 94.92 & 70.0 & 94.9 \\
\hline
\end{tabular}

AUC: Area Under a Curve, P value: Probability value, CI: Confidence Intervals.

Table 7. Agreement (sensitivity, specificity) for CV. eGFR to predict CIN cases for non-diabetic cases $(\mathrm{n}=35)$.

\begin{tabular}{cccccc}
\hline & Cut off & Sensitivity & Specificity & PPV & NPV \\
\hline CV. eGFR & $>5.2$ & 80.0 & 96.43 & 80.0 & 96.4 \\
\hline
\end{tabular}

Table 8. Agreement (sensitivity, specificity) for CV. eGFR to predict CIN cases for diabetic cases $(\mathrm{n}=38)$.

\begin{tabular}{cccccc}
\hline & Cut off & Sensitivity & Specificity & PPV & NPV \\
\hline CV.eGFR & $>7$ & 60.0 & 96.77 & 75.0 & 93.7 \\
\hline
\end{tabular}

Table 9. Comparison between the three studied groups according to procedure.

\begin{tabular}{|c|c|c|c|c|c|c|c|c|}
\hline \multirow{2}{*}{ Procedure } & \multicolumn{2}{|c|}{ Group A $(n=24)$} & \multicolumn{2}{|c|}{ Group B $(n=26)$} & \multicolumn{2}{|c|}{ Group C $(n=23)$} & \multirow{2}{*}{$x^{2}$} & \multirow{2}{*}{$\mathrm{MCp}$} \\
\hline & No. & $\%$ & No. & $\%$ & No. & $\%$ & & \\
\hline Elective & 17 & 73.9 & 23 & 88.5 & 18 & 80.0 & \multirow{2}{*}{1.753} & \multirow{2}{*}{0.434} \\
\hline Primary & 7 & 26.1 & 3 & 11.5 & 5 & 20.0 & & \\
\hline
\end{tabular}

$\chi^{2}$ : iChi square test; MC: Monte Carlo; $\mathrm{p}$ : $\mathrm{p}$ value for comparing between the three groups overall number of elective PCI procedures was 56 cases and 14 primary PCI procedures. Number of elective procedures in group A was 17 cases (73.9\%) and 7 primary cases and in group B elective cases was 23 (88.5\%) and 3 primary cases (11.5\%) and in group C 16 elective (80\%) and 4 primary cases $(20 \%)$.

Table 10. Comparison between the three studied groups according to Amount dye.

\begin{tabular}{cccc}
\hline Amount of dye & Group A $(\mathbf{n}=\mathbf{2 4})$ & Group B $(\mathbf{n}=\mathbf{2 6})$ & Group C ( $\mathbf{n}=\mathbf{2 3})$ \\
\hline Min. - Max. & $40.0-80.0$ & $90.0-150.0$ & $200.0-450.0$ \\
Mean \pm SD. & $58.26 \pm 15.05$ & $109.42 \pm 17.11$ & $304.5 \pm 60.30$ \\
Median & 60.0 & 105.0 & 300.0 \\
\hline
\end{tabular}

F: F for ANOVA test, Pairwise comparison bet. each 2 groups was done using Post Hoc Test (Tukey). 
All cases were done using low-osmolar non ionic contrast. Type A lesions were 23 cases $(32.8 \%)$ and type B were 34 cases (48.7\%), while type C lesions were 13 cases $(18.5 \%)$. There was with no statistically significance $(\mathrm{p}=0.006)$ between the 3 groups Table 11 .

In group $\mathrm{A}$ incidence of CIN, Dialysis and mortality was $0 \%$.

In group $\mathrm{B}$ there was $11.5 \% \mathrm{CIN}$ and $11.5 \%$ dialysis and $0 \%$ mortality.

In group $\mathrm{C}$ incidence of CIN was $35.5 \%$ and $26 \%$ dialysis and $17 \%$ mortality.

Overall incidence of CIN was $0,11.5 \%, 35 \%$, overall incidence of dialysis was $0,11.5 \%, 26 \%$ while overall incidence of mortality was 0,0 , and $17 \%$.

There is strong statistically significance between the 3 groups Table 12 .

Syntax score was measured for all cases, in group A the syntax score was ranging between 2 and 21 and in group $B$ range between 3-22, in group $C$ ranging between 7 - 22 .

There were no statistically significant difference between the 3 groups $(\mathrm{p}=$ 0.057) Table 13.

Table 11. Comparison between the three studied groups according to type contrast and type lesion.

\begin{tabular}{ccccccccc}
\hline & \multicolumn{7}{c}{ Group A $(\mathrm{n}=24)$} & \multicolumn{2}{c}{ Group B $(\mathrm{n}=26)$} & Group C $(\mathrm{n}=23)$ & \multirow{2}{*}{$\chi^{2}$} & p \\
\cline { 2 - 7 } & No. & $\%$ & No. & $\%$ & No. & $\%$ & & \\
\hline $\begin{array}{c}\text { Type contrast } \\
\text { Low osmolar } \\
\text { Type lesion }\end{array}$ & 24 & 100.0 & 26 & 100 & 20 & 100 & & \\
A & 12 & 52.1 & 9 & 39.1 & 2 & 8.6 & \multirow{2}{*}{$12.478 \quad \mathrm{MCp}=0.006$} \\
B & 9 & 23.5 & 18 & 52.94 & 7 & 20.5 & & \\
C & 2 & 15.3 & 1 & 7.69 & 10 & 76.9 & & \\
\hline
\end{tabular}

$\chi^{2}$ : iChisquare; MC: Monte Carlo; ${ }^{*}$ Statistically significant at $\mathrm{p} \leq 0.05$.

Table 12. Comparison between the three studied groups according to CIN incidence, dialysis and mortality.

\begin{tabular}{ccccccccc}
\hline & \multicolumn{2}{c}{ Group A $(\mathrm{n}=24)$} & \multicolumn{2}{c}{ Group B $(\mathrm{n}=26)$} & Group C $(\mathrm{n}=23)$ & \multirow{2}{*}{$\chi^{2}$} & \multirow{2}{*}{ MCp } \\
\cline { 2 - 7 } & No. & $\%$ & No. & $\%$ & No. & $\%$ & & \\
\hline Mortality & 0 & 0.0 & 0 & 0.0 & 4 & 17 & $5.184^{*}$ & $0.021^{*}$ \\
CIN & 0 & 0.0 & 3 & 11.5 & 8 & 35.5 & $10.207^{*}$ & $0.003^{*}$ \\
Dialysis & 0 & 0.0 & 3 & 11.5 & 6 & 26 & $12.309^{*}$ & $<0.001^{*}$ \\
\hline
\end{tabular}

$\chi^{2}$ : Chi square; MC: Monte Carlo; $\mathrm{p}: \mathrm{p}$ value for comparing between the three groups; ${ }^{*}$ : Statistically significant at $\mathrm{p} \leq 0.05$.

Table 13. Comparison between the three studied groups according to syntax score.

\begin{tabular}{cccccc}
\hline Syntax score & Group A $(\mathrm{n}=24)$ & Group B $(\mathrm{n}=26)$ & Group C $(\mathrm{n}=23)$ & $\mathrm{H}$ & $\mathrm{p}$ \\
\hline Min. - Max. & $2.0-21.0$ & $3.0-22.0$ & $7.0-22.0$ & & \\
Mean \pm SD. & $8.39 \pm 5.52$ & $9.23 \pm 4.62$ & $10.15 \pm 4.28$ & 5.728 & 0.057 \\
Median & 7.0 & 8.0 & 8.0 & & \\
\hline
\end{tabular}

$\mathrm{H}: \mathrm{H}$ for Kruskal Wallis test. 


\section{Discussion}

Contrast-induced nephropathy is defined as impairment of renal function occurring within 48 hours after administration of contrast medium. It's manifested by an increase in serum creatinine level of $0.5 \mathrm{mg} / \mathrm{dl}$ or by a relative increase of $25 \%$ over the baseline value [18].

This study suggests that PCI can be done in moderate and severe chronic kidney disease patients with elevated serum creatinine levels and e-GFR $<60$ $\mathrm{mL} / \mathrm{min} / 1.73 \mathrm{~m}^{2}$ safely without incidence of CIN, dialysis or mortality using low dose contrast protocol even without IVUS use.

CKD is defined as kidney damage or glomerular filtration rate (GFR) $<60$ $\mathrm{mL} / \mathrm{min} / 1.73 \mathrm{~m}^{2}$ for 3 months or more, irrespective of cause. This definition is accepted by Kidney Disease Quality Outcome Initiative (K/DOQI) [19].

The current study includes $73 \mathrm{CAD}$ patients with moderate to severe kidney impairment with e-gfr $<60 \mathrm{ml} / \mathrm{kg} / 1.73 \mathrm{~min}$ indicated for percutaneous coronary intervention. The patients were divided into 3 groups according to the amount of dye:

Group (A): which included [20] whose cv/gfr ratio $<2$.

Group (B): which included [21] patients in whom cv/gfr ratio $>2$ but still $<$ MACD.

Group (C): which included [22] patients in whom the cv/gfr ratio has exceeded MACD.

In group (A) PCI was done to 23 patients with e-GFR ranging between 22.38 58.25 with mean $37.69 \pm 10.06$ using a minimized amount of dye by low dose protocol and CV was restricted using cv/e-GFR ratio $<2$.

Surprisingly none of the 24 patients of group (A) developed CIN; which is defined as a rise of serum creatinine level. $5 \mathrm{mg} / \mathrm{dl}$ or $25 \%$ above basal serum creatinine and also $0 \%$ incidence of dialysis and mortality.

Keshav R. Nayak et al. described a novel technique to minimize contrast during $\mathrm{PCI}$ in patients with severe kidney impairment whose e-GFR $<30 \mathrm{~mL} / \mathrm{min} / 1.73 \mathrm{~m}^{2}$.

They reported 3 cases of CAD with e-GFR $<30 \mathrm{~mL} / \mathrm{min} / 1.73 \mathrm{~m}^{2}$, PCI was done to RCA, LAD, RCA using $7.5,14,10 \mathrm{ml}$ contrast using IVUS. The $4^{\text {th }}$ patient underwent a diagnostic study and multi-vessel PCI without the use of any contrast media using previous angiographic images and extensive intravascular ultrasound (IVUS) employment. None of the 4 patients showed any deterioration of renal function during a 7-day follow-up period [21].

This is similar to a study by N.Ogata et al. PCI was done in 18 patients with e-GFR $<30 \mathrm{~mL} / \mathrm{min} / 1.73 \mathrm{~m}^{2}$ using ultra low dose protocol or maximum minimized contrast protocol with cv/e-GFR $<1$, IVUS use has helped in minimizing amount of contrast. The overall incidence of CIN was $0 \%$ and $0 \%$ in dialysis and mortality [15].

Although cv/e-GFR was different with extreme reduction in the Japanese study, incidence was the same in our study because we included patients with e-GFR $<60 \mathrm{~mL} / \mathrm{min} / 1.73 \mathrm{~m}^{2}$ i.e. moderate to severe kidney disease, while N. Ogata 
et al. all patients were e-GFR $<30 \mathrm{~mL} / \mathrm{min} / 1.73 \mathrm{~m}^{2} \mathrm{ml} / \mathrm{kg} / \mathrm{min}$ and the relatively small number of patients in both studies.

Mehran et al. previously published a simple risk score for CI-AKI after PCI based on a retrospective large cohort analysis. According to Mehran et al. incidence of CIN in CKD patients was 30\% [22].

In our study, CIN incidence in group (C) which had relatively large amounts of dye was $35 \%$.

According to a study by Zach Rozenbaum et al. 30 patients with stage $3 \mathrm{~b}-5$ chronic kidney disease referred for coronary angiography. The most common indication was NSTEMI ( 25 patients) followed by stable angina pectoris (5 patients), and 16 patients underwent subsequent coronary angioplasty. CIN occurred in 3 patients increase in serum cystine level but not on creatinine levels $48 \mathrm{~h}$ following coronary procedure [20].

Safe limit for contrast use has been studied in many studies. Maximum allowed contrast dose calculated as 5 times body weight/serum creatinine has been reported.

This formula has been applied retrospectively in 16,592 patients undergoing cardiac catheterization to determine its utility in predicting the risk of post-procedural dialysis [23].

Cigorra et al. has also validated this formula in 115 patients with chronic kidney disease (serum creatinine above $1.8 \mathrm{mg} / \mathrm{dl}$ ) underwent cardiac catheterization and angiography, after which the level serum creatinine was measured daily for five days. The amount of contrast material that was given adhered to the limit in 86 patients (Group I) and exceeded it in 29 (Group II). Contrast-induced renal dysfunction (an increase in serum creatinine greater than or equal to 1.0 $\mathrm{mg} / \mathrm{dL}$ ) occurred in two (2\%) patients in Group I and in six (21\%) patients in Group II $(\mathrm{p}<0.001)$ [11].

In our study PCI was performed on 20 patients with CKD, e-GFR less than 60 $\mathrm{ml} / \mathrm{min} \backslash 1.72 \mathrm{~m}$ using amounts of contrast exceeding MACD ( 5 bodyweight/serum creatinine) without application of low dose contrast protocol. CIN occurred in 7 patients (35\%) and 30\% required dialysis and $15 \%$ deaths.

The most important risk factor for nephropathy after exposure to iodinated contrast media is preexisting renal impairment. The risk of CIN is elevated and becomes clinically important in patients with chronic kidney disease characterized by an estimated glomerular filtration rate $<60 \mathrm{~mL} / \mathrm{min} / 1.73 \mathrm{~m}$.

As a result contrast volume to creatinine clearance has been studied [18] [24] [25]. Altmann DB et al. studied contrast volume to creatinine clearance in 152 CKD Patients and found that cut off value of 6 is predictive of CI-AKI [26].

This is similar to our results: ROC curve for CV/eGFR to predict cut-off value for CIN for total number of cases (70) was done with cut-off value $>6$ and sensitivity $70 \%$, specificity $94.92 \%$ and PPV $70.0 \%$ and NPV $94.5 \%$.

The cut-off value to predict CIN was calculated for both diabetics and non-diabetic patients using ROC-curve analysis for CV/e-GFR. 
.For non-diabetic patients a cut-off value $>5.2$ is predictor with Sensitivity 80\% and specificity 96.43iand PPV 80\%iandiNPVi $96.4 \%$.

For diabetic patients, a cut-off value $>7$ is predictor with Sensitivity $60 \%$ and specificity $96.77 \%$ and PPV $75 \%$ and NPV $93.7 \%$.

According to a study by Laskey et al. on 3179 patients, cv/cc over 3.7 was a strong and independent predictor of CI-AKI [12].

Also cv/e-gfr ratio $<1$ was used in a study by N.ogata et al. on 18 patients with severe kidney impairment e-GFR $<30 \mathrm{~mL} / \mathrm{min} / 1.73 \mathrm{~m}^{2}$ and $0 \%$ incidence of CIN, Dialysis, and mortality. According to these investigators cv/e-GFR $<1$ was a safe margin in severe CKD and should be a target of IVUS guided PCI [15].

According to our study cv/e-GFR $<2$ was safe and reasonable margin for contrast use especially in moderate CKD and in absence of IVUS as a tool to minimize contrast as none of our patients developed CIN, Dialysis or mortality.

\section{Study Limitations}

The current study had the following limitations:

1) The sample size was rather small and the follow-up time was short-term.

2) Selection bias towards a more simple lesion.

3) Application of low dose contrast in complex bifurcation and CTO needs further research and expert operators

4) Rational of minimized contrast in this study i.e. CV/e-GFR $<2$ was relatively small as its single-center study and rationale of low dose contrast in CKD patients is still underutilized in real-world practice due to fear of renalism.

\section{Conclusion}

1) PCI can be done in moderate to severe kidney impairment e-GFR $<60$ $\mathrm{mL} / \mathrm{min} / 1.73 \mathrm{~m}^{2}$ using low dose contrast protocol without CIN or dialysis.

2) Low dose contrast protocol is easy and applicable approach in CKD pts during pci especially in simple pci and coronary angiography group.

3) CV/e-GFR $<2$ is a safe limit to minimize contrast in CKD pts mainly moderate to severe disease. Further studies need to be done on severe CKD e-GFR < $30 \mathrm{~mL} / \mathrm{min} / 1.73 \mathrm{~m}^{2}$.

4) CV/e-GFR is one of predictors of CI-AKI in CKD pts during pci with cut-off value $>6$ to predict CIN.

5) CV/e-gfr $<1$ can be achieved and may be a target of ivus guided PCI.

6) Complex pci i.e. bifurcation and CTO in CKD pts can be done using low dose contrast protocol but need expert operator and IVUS guidance.

\section{Recommendations}

1) CKD patients needing PCI shouldn't be deferred due to fear of renalism especially who needs primary PCI with contraindication or failed thrombolytic therapy.

2) Such kind of patients PCI can be done with low dose contrast protocol. 
3) CV/e-gfr ratio $<2$ is accepted ratio to minimize contrast especially in moderate to severe kidney disease and absence of IVUS and in primary PCI.

4) Further reduction to CV/e-GFR $<1$ should be targeted to IVUS guided PCI.

5) CKD with e-GFR $<30 \mathrm{~mL} / \mathrm{min} / 1.73 \mathrm{~m}^{2}$ and complex anatomy i.e. bifurcation or CTO should be performed by expert operator in such techniques and in ivus use.

6) Potentially nephrotoxic drugs, including aminoglycoside antibiotics, anti-rejection medications, metformin and non-steroidal anti-inflammatory drugs (NSAIDs) should be withheld before the procedure which is also not applicable during emergent situations.

7) Dehydration should be avoided; hydration has been proven to be safe, cheap, effective and rapid method that can be easily applied to all patients and during emergency (e.g; primary PCI). Therefore prophylaxis is crucial, especially in patients considered to be at high risk for CIN.

8) Using low or iso-osmolar contrast agents in patients at risk for development of CIN.

\section{Conflicts of Interest}

The authors declare no conflicts of interest regarding the publication of this paper.

\section{References}

[1] Abe, M., Kimura, T., Morimoto, T., Furukawa, Y. and Kita, T. (2009) Incidence of and Risk Factors for Contrast-Induced Nephropathy after Cardiac Catheterization in Japanese Patients. Circulation Journal, 73, 1518-1522.

https://doi.org/10.1253/circj.CJ-08-0784

[2] Gruberg, L., Mintz, G.S., Mehran, R., Gangas, G., Lansky, A.J., Kent, K.M., Pichard, A.D., Satler, L.F. and Leon, M.B. (2000) The Prognostic Implications of Further Renal Function Deterioration within $48 \mathrm{~h}$ of Interventional Coronary Procedures in Patients with Pre-Existent Chronic Renal Insufficiency. Journal of the American College of Cardiology, 36, 1542-1548. https://doi.org/10.1016/S0735-1097(00)00917-7

[3] Goldenberg, I., Chonchol, M. and Guetta, V. (2009) Reversible Acute Kidney Injury Following Contrast Exposure and the Risk of Long-Term Mortality. American Journal of Nephrology, 29, 136-144. https://doi.org/10.1159/000151772

[4] Mager, A., VakninAssa, H., Lev, E.I., Bental, T., Assali, A. and Kornowski, R. (2011) The Ratio of Contrast Volume to Glomerular Filtration Rate Predicts Outcomes after Percutaneous Coronary Intervention for ST-Segment Elevation Acute Myocardial Infarction. Catheterization and Cardiovascular Interventions, 78, 198-201. https://doi.org/10.1002/ccd.22828

[5] Kawamura, Y., Morino, Y., Nagaoka, M., Matsukage, T., Masuda, N. and Ikari, Y. (2011) Impact of Chronic Kidney Disease on Clinical and Angiographic Results Following Implantation of Sirolimus-Eluting Coronary Stents. Cardiovascular Intervention and Therapeutics, 26, 18-25. https://doi.org/10.1007/s12928-010-0029-9

[6] Morikawa, S., Sone, T., Tsuboi, H., Mukawa, H., Morishima, I., Uesugi, M., Morita, 
Y., Numaguchi, Y., Okumura, K. and Murohara, T. (2009) Renal Protective Effects and the Prevention of Contrast-Induced Nephropathy by Atrial Natriuretic Peptide. Journal of the American College of Cardiology, 53, 1040-1046. https://doi.org/10.1016/j.jacc.2008.10.061

[7] Chen, H.H. (2009) Atrial Natriuretic Peptide for the Prevention of Contrast Induced Nephropathy: What's Old Is New But at the Right Dose and Duration of Therapy! Journal of the American College of Cardiology, 53, 1047-1049. https://doi.org/10.1016/j.jacc.2008.12.020

[8] Kawashima, S., Takano, H., Iino, Y., Takayama, M. and Takano, T. (2006) Prophylactic Hemodialysis Does Not Prevent Contrast-Induced Nephropathy after Cardiac Catheterization in Patients with Chronic Renal Insufficiency. Circulation Journal, 70, 553-558. https://doi.org/10.1253/circj.70.553

[9] Nijssen, E.C., Nelemans, P.J., Rennenberg, R.J., van Ommen, V. and Wildberger, J.E. (2018) Prophylactic Intravenous Hydration to Protect Renal Function from Intravascular Iodinated Contrast Material: AMACING, Long-Term Results of a Prospective, Randomised, Controlled Trial.

[10] Chertow, G.M., Normand, S.L. and McNeil, B.J. (2004) Renalism: Inappropriately Low Rates of Coronary Angiography in Elderly Individuals with Renal Insufficiency. Journal of the American Society of Nephrology, 15, 2462-2468. https://doi.org/10.1097/01.ASN.0000135969.33773.0B

[11] Cigarroa, R.G., Lange, R.A., Williams, R.H. and Hillis, L.D. (1989) Dosing of Contrast Material to Prevent Contrast Nephropathy in Patients with Renal Disease. The American Journal of Medicine, 86, 649-652. https://doi.org/10.1016/0002-9343(89)90437-3

[12] Laskey, W.K., Jenkins, C., Selzer, F., Marroquin, O.C., Wilensky, R.L., Glaser, R., Cohen, H.A. and Holmes, D.R. (2007) Volume-to-Creatinine Clearance Ratio: A Pharmacokinetically Based Risk Factor for Prediction of Early Creatinine Increase after Percutaneous Coronary Intervention. Journal of the American College of Cardiology, 50, 584-590. https://doi.org/10.1016/j.jacc.2007.03.058

[13] Barrett, B.J. and Parfrey, P.S. (2006) Clinical Practice. Preventing Nephropathy Induced by Contrast Medium. The New England Journal of Medicine, 354, 379-386. https://doi.org/10.1056/NEJMcp050801

[14] Kane, G.C., Doyle, B.J., Lerman, A., Barsness, G.W., Best, P.J. and Rihal, C.S. (2008) Ultra-Low Contrast Volumes Reduce Rates of Contrast-Induced Nephropathy in Patients with Chronic Kidney Disease Undergoing Coronary Angiography. Journal of the American College of Cardiology, 51, 89-90. https://doi.org/10.1016/j.jacc.2007.09.019

[15] Ogata, N., Matsukage, T., Toda, E., Tamiya, S., Fujii, T., Nakazawa, G., Masuda, N., Morino, Y. and Ikari, Y. (2011) Intravascular Ultrasound-Guided Percutaneous Coronary Interventions with Minimum Contrast Volume for Prevention of the Radiocontrast-Induced Nephropathy: Report of Two Cases. Cardiovascular Intervention and Therapeutics, 26, 83-88. https://doi.org/10.1007/s12928-010-0037-9

[16] Neumann, F.-J., Sousa-Uva, M., Ahlsson, A., Alfonso, F., Banning, A.P., Benedetto, U., Byrne, R.A, Collet, J.-P., Falk, V., Head, S.J, Jüni, P., Kastrati, A., Koller, A., Kristensen, S.D., Niebauer, J., Richter, D.J., Seferović, P.M., Sibbing, D., Stefanini, G.G., Windecker, S., Yadav, R., Zembala, M.O. and ESC Scientific Document Group (2018) ESC/EACTS Guidelines on Myocardial Revascularization. https://doi.org/10.5603/KP.2018.0228

[17] Imai, E., Horio, M., Nitta, K., Yamagata, K., Iseki, K., Hara, S., Ura, N., Kiyohara, 
Y., Hirakata, H., Watanabe, T., Moriyama, T., Ando, Y., et al. (2007) Estimation of Glomerular Filtration Rate by the MDRD Study Equation Modified for Japanese Patients with Chronic Kidney Disease. Clinical and Experimental Nephrology, 11, 41-50.

[18] McCullough, P.A., Adam, A., Becker, C.R., Davidson, C., Lameire, N., Stacul, F. and Tumlin, J. (2006) Risk Prediction of Contrast-Induced Nephropathy. American Journal of Cardiology, 98, 27K-36K. https://doi.org/10.1016/j.amjcard.2006.01.022

[19] Levey, A.S., Eckardt, K.-U., Tsukamoto, Y. and Levin, A. (2005) Definition and Classification of Chronic Kidney Disease: A Position Statement from Kidney Disease: Improving Global Outcomes (KDIGO). Kidney International, 67, 2089-2100.

[20] Rozenbaum, Z., Benchetrit, S., Rozenbaum, E., Neumark, E., Mosseri, M. and Pereg, D. (2018) Ultra-Low Contrast Volume for Patients with Advanced Chronic Kidney Disease Undergoing Coronary Procedures. Nephron, 138, 296-302. https://www.karger.com/Article/FullText/485648

[21] Nayak, K.R., Mehta, H.S., Russo, R.J., Stinis, C.T., Moses, J.W., Mehran, R. and Leon, M.B. (2010) A Novel Technique for Ultra-Low Contrast Administration during Angiography or Intervention. Catheterization and Cardiovascular Interventions, 75, 1076-1083. https://onlinelibrary.wiley.com/doi/full/10.1002/ccd.22414

[22] Mehran, R., Aymong, E.D., Nikolsky, E., Lasic, Z., Iakovou, I., Fahy, M., Mintz, G.S., Lansky, A.J., Moses, J.W., Stone, G.W., Leon, M.B. and Dangas, G. (2004) A Simple Risk Score for Prediction of Contrast-Induced Nephropathy after Percutaneous Coronary Intervention: Development and Initial Validation. Journal of the American College of Cardiology, 44, 1393-1399. https://doi.org/10.1016/S0735-1097(04)01445-7

[23] Freeman, R.V., O’Donnell, M., Share, D., Meengs, W.L., Kline-Rogers, E., Clark, V.L., DeFranco, A.C., Eagle, K.A., McGinnity, J.G., Patel, K., Maxwell-Eward, A., Bondie, D. and Moscucci, M. (2002) Nephropathy Requiring Dialysis after Percutaneous Coronary Intervention and the Critical Role of an Adjusted Contrast Dose. American Journal of Cardiology, 90, 1068-1073. https://doi.org/10.1016/S0002-9149(02)02771-6

[24] Nyman, U., Bjork, J., Aspelin, P. and Marenzi, G. (2008) Contrast Medium Dose to-GFR Ratio: A Measure of Systemic Exposure to Predict Contrast Induced Nephropathy after Percutaneous Coronary Intervention. Acta Radiologica, 49, 658-667. https://doi.org/10.1080/02841850802050762

[25] Azzalini, L., Laricchia, A., Regazzoli, D., Mitomo, S., Hachinohe, D., Bellini, B., Demir, O.M., Poletti, E., Maccagni, D. and Colombo, A. (2019) Ultra-Low Contrast Percutaneous Coronary Intervention to Minimize the Risk for Contrast-Induced Acute Kidney Injury in Patients with Severe Chronic Kidney Disease. Journal of Invasive Cardiology, 31, 176-182.

[26] Altmann, D.B., Zwas, D., Spatz, A., Bergman, G., Spokojny, A., Rivai, S. and Sanborn, T.A. (1997) Use of the Contrast Volume to Estimated Creatinine Clearance Ratio to Predict Renal Failure after Angiography. Journal of Interventional Cardiology, 10, 113-119. https://doi.org/10.1111/j.1540-8183.1997.tb00018.x 